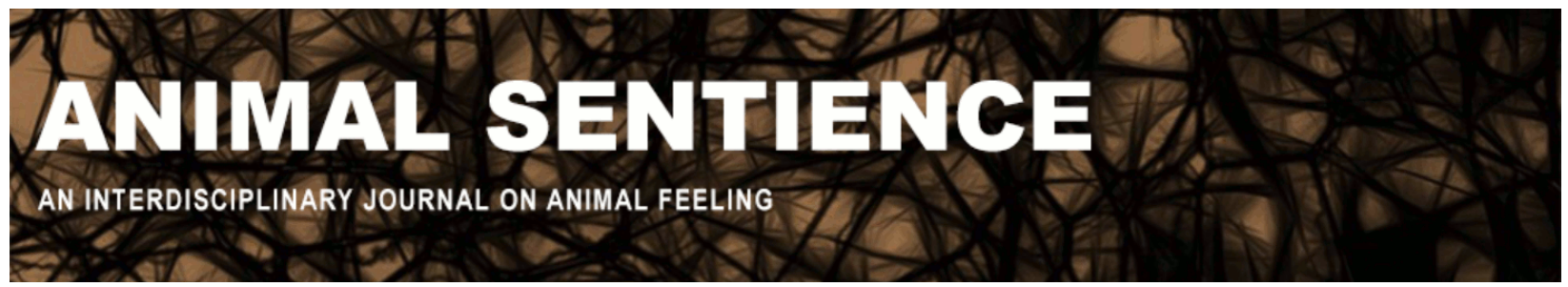

Favela, Luis H. (2017) Mental representations are not necessary for fish consciousness. Animal Sentience 13(9)

DOI: $10.51291 / 2377-7478.1243$

Date of submission: 2017-11-05

Date of acceptance: 2017-11-07

(c) $\underset{\mathrm{EY}}{\mathrm{C}}$

This article has appeared in the journal Animal

Sentience, a peer-reviewed journal on animal

cognition and feeling. It has been made open access,

free for all, by WellBeing International and deposited

in the WBI Studies Repository. For more information,

please contact

wbisr-info@wellbeingintl.org.

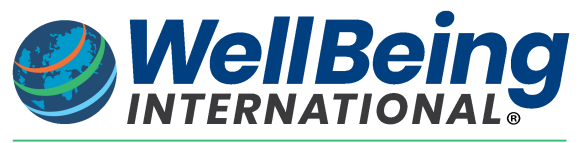

SOLUTIONS FOR PEOPLE, ANIMALS AND ENVIRONMENT 


\title{
Mental representations are not necessary for fish consciousness
}

\author{
Commentary on Woodruff on Fish Feel
}

\author{
Luis H. Favela \\ Department of Philosophy and Cognitive Sciences Program \\ University of Central Florida
}

\begin{abstract}
Woodruff (2017) argues that teleost fishes are capable of phenomenal consciousness. Central to his argument is the assumption that phenomenal consciousness is representational in nature. I think the commitment to a representational theory of consciousness undermines Woodruff's case for teleost phenomenal consciousness. The reason is that organisms do not need to perceive the world indirectly via mental images/representations in order to have phenomenological experiences. My argument is based on considerations of ecological psychology and comparative ethology.
\end{abstract}

Luis H. Favela is Assistant Professor of
Philosophy and Cognitive Sciences at the
University of Central Florida. His
interdisciplinary research at the intersection of
philosophy and the mind sciences applies
complexity science and dynamical systems
theory to investigations of behavior, cognition,
and consciousness in diverse systems at
various scales. http://luishfavela.com/

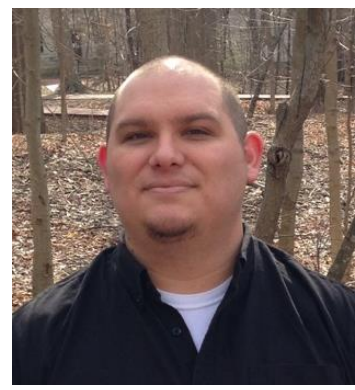

Woodruff (2017) argues that teleost fishes are capable of phenomenal consciousness. He begins with the assumption that to attempt to understand whether nonhuman organisms have consciousness is to be a good Darwinian and to treat them and humans as having evolutionarily continuous anatomical structures and behavioral capacities. He accordingly provides a great deal of compelling evidence of neuroanatomical, neurophysiological, and behaviorally relevant continuity between fish and humans to suggest that if the latter have phenomenal consciousness, then so too do the former. However, Woodruff's argument is weakened by another assumption, namely, that phenomenal consciousness is representational in nature (pp. 4, 6-7, 13-15). Following Feinberg and Mallatt (2016), Woodruff takes it as "axiomatic" that mental images (i.e., mental representations) contribute to the something-it-is-like-to-be feature of phenomenal consciousness and, thus, sentience (Woodruff, 2017, p. 4). I think the mental images/representations assumption undermines Woodruff's case for teleost phenomenal consciousness. The reason is that organisms do not need to perceive the world indirectly via mental images/representations in order to have phenomenal consciousness. Note that in what follows I abbreviate phenomenal consciousness as 'consciousness' and mental image/representation as 'representation.'

Woodruff implicitly endorses a representational theory of consciousness. In general, such theories hold that conscious mental states are about something (i.e., they are "intentional"), where that something is a depiction of other states, including the current state of the world (e.g., an apple on the desk in front of you), memories (e.g., recalling how many 
windows your childhood home had), and imagination (e.g., thinking about a unicorn walking on a cloud; Gennaro, 2012; Lycan, 2015). This ability to represent states mentally is central to Woodruff's (2017) argument: "The neural representation of the world in the tectum is experienced subjectively as mental images," which "is an important insight into what it means for a neural system to participate in the generation of sentience" (p. 4). Woodruff asserts that such representations are crucial for "directed, adaptive global motor output" (pp. 3-4). Vision, for example, begins in the "point-by-point representation of visual space on the retina," which is then transformed into a "isomorphic neural representation of visual space," which is then transformed into a visual mental image (p. 4). This assumption actually weakens Woodruff's case for teleost consciousness. It is in fact not necessary for information about the world to be transformed into isomorphic representations in order to direct adaptive motor behavior. Moreover, such perceptions of the world need not be representational in order to be phenomenological.

One of the primary reasons often invoked to motivate the need for representations in perception is that the stimulus provided by the world to the organism is too impoverished to act upon. The retinal image alone, for instance, cannot discriminate distance, for example, that a tree that is small and near can cast the same retinal image as a tree that is larger and farther away. Consequently, the representationalist asserts that the retinal image must be supplemented with information stored in the mind, for example, cuing depth based on surface orientation (Marr, 1982/2010). Ecological psychologists argue on empirical and theoretical grounds that perception is direct. Even then, they agree that the retinal-image alone is insufficient to guide action. However, instead of going inward into the mind to find additional information, ecological psychologists go outward into the environment (Favela, 2016; Gibson, 1979/1986). According to this view, visual perception is not isolated in the brain or distinct from action. Perception and action are inextricably connected and occur across perceptual systems that include the brain, body, and environment. For example, whereas the representationalist holds that mentally stored information about surface orientation cues depth, the ecological psychologist holds that temporal and movement-based features of the environment such as parallax can reveal depth. The former view requires information about the world to come from the mind; the latter derives it from the world itself. Thus, the environment serves as a rich source of information for visually guided action.

If the world serves as its own best model (Brooks, 1991), then environments can serve as rich sources of information. If so, then there would be no need to appeal to representations to explain how organisms conduct successful goal-directed and adaptable behavior. Consider how very different anatomical structures of various organisms utilize visual information to guide action: compound eyes of fruit flies, convex lenses of lobsters, and crystalline holochroal eyes of trilobites. These organisms have no retina and thus they cannot create isomorphic neural representations of visual space to transform into indirect visual mental representations. Yet fruit flies can dodge a swatter based on visual information. How can that be if the fruit fly has neither retina nor neural or mental representations? It is because the fruit fly visually perceives the world directly: so too does the lobster and trilobite. They are able to base adaptive action on direct perceptions because the environment is rich with information. This is also the case for other organisms, even those with retinae such as birds, fish, and mammals. It is important to make clear here that proponents of direct perception do not go from the claim that perception 
need not be representational to the claim that perception is without phenomenological experience. On the contrary, proponents of direct perception are often focused on the phenomenal nature of perception (Favela \& Chemero, 2016; Soteriou, 2014).

Although representations are commonly appealed to in philosophy and the cognitive, neural, and psychological sciences in accounts of phenomena such as visual perception, the truth is that "representations" are far from understood (Chemero, 2009; Freeman \& Skarda, 1990; Gallagher, 2008; Lycan, 2015; Ramsey, 2007).

Regarding Woodruff's representational assumption in particular, my suggestion is that the case for teleost consciousness can be more compelling if we focus on the ways fish perceive the world directly instead of trying to explain how mental images are constructed. This is because fish do not need, and probably do not have, mental images for their ability to perceive and act in the world. This by no means implies that fish do not have visual phenomenological experiences - just that those experiences need not be representational in nature.

\section{References}

Brooks, R. A. (1991). Intelligence without representation. Artificial Intelligence, 47, 139-159.

Chemero, A. (2009). Radical embodied cognitive science. Cambridge, MA: MIT Press.

Favela, L. H. (2016). Commentary: Purves, Morgenstern, \& Wojtach. (2015). Perception and reality: Why a wholly empirical paradigm is needed to understand vision. Frontiers in Systems Neuroscience, 10(77). doi:10.3389/fnsys.2016.00077

Favela, L. H., \& Chemero, A. (2016). An ecological account of visual "illusions." Florida Philosophical Review, 16, 68-93.

Feinberg, T. E., \& Mallatt, J. M. (2016). The ancient origins of consciousness: How the brain created experience. Cambridge, MA: MIT Press.

Freeman, W. J., \& Skarda, C. A. (1990). Representations: Who needs them? In J. L. McGaugh, N. M. Weinberger, \& G. Lynch (Eds.), Brain organization and memory: Cells, systems, and circuits (pp. 375-380). New York, NY: Oxford University Press.

Gallagher, S. (2008). Are minimal representations still representations? International Journal of Philosophical Studies, 16, 351-369.

Gennaro, R. J. (2012). The consciousness paradox: Consciousness, concepts, and higher-order thoughts. Cambridge, MA: MIT Press.

Gibson, J. J. (1979/1986). The ecological approach to visual perception. Boston, MA: Houghton Mifflin.

Lycan, W. (2015). Representational theories of consciousness. In E. N. Zalta (Ed.), The Stanford encyclopedia of philosophy (Summer 2015 edition). Retrieved from https://plato.stanford.edu/archives/sum2015/entries/consciousness-representational/.

Ramsey, W. M. (2007). Representation reconsidered. New York, NY: Cambridge University Press.

Soteriou, M. (2014). The disjunctive theory of perception. In E. N. Zalta (Ed.), The Stanford encyclopedia of philosophy (Winter 2016 edition). Retrieved from https://plato.stanford.edu/archives/win2016/entries/perception-disjunctive/.

Woodruff, M. L. (2017). Consciousness in teleosts: There is something it feels like to be a fish. Animal Sentience 13(1). 


\section{ANIMAL CONSCIOUSNESS}

On November 17-18, 2017, the NYU Center for Mind, Brain and Consciousness, the NYU Center for Bioethics, and NYU Animal Studies will host a conference on Animal Consciousness.

This conference will bring together philosophers and scientists to discuss questions such as: Are invertebrates conscious? Do fish feel pain? Are nonhuman mammals self-conscious? How did consciousness evolve? How does research on animal consciousness affect the ethical treatment of animals? What is the impact of issues about animal consciousness on theories of consciousness and vice versa? What are the best methods for assessing consciousness in nonhuman animals?

\section{Speakers and panelists include:}

Colin Allen (University of Pittsburgh, Department of History \& Philosophy of Science), Andrew Barron (Macquarie, Cognitive Neuroethology), Victoria Braithwaite (Penn State, Biology), Peter Carruthers (Maryland, Philosophy), Marian Dawkins (Oxford, Zoology), Dan Dennett (Tufts, Philosophy), David Edelman (San Diego, Neuroscience),

Todd Feinberg (Mt. Sinai, Neurology), Peter Godfey-Smith (Sydney, Philosophy), Lori Gruen (Wesleyan, Philosophy), Brian Hare (Duke, Evolutionary Anthropology), Stevan Harnad (Montreal, Cognitive Science), Eva Jablonka (Tel Aviv, Cohn Institute), Björn Merker (Neuroscience), Diana Reiss (Hunter,

Psychology), Peter Singer (Princeton, Philosophy), Michael Tye (Texas, Philosophy)

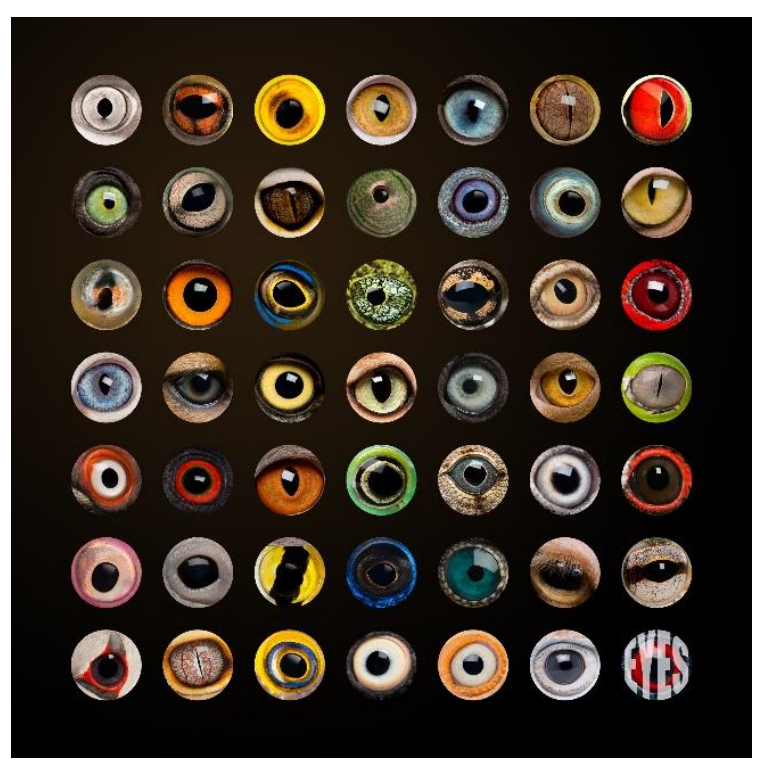

Organizers: Ned Block, David Chalmers, Dale Jamieson, S. Matthew Liao.

The conference will run from 9am on Friday November 17 to $6 \mathrm{pm}$ on Saturday November 18 at the NYU Cantor Film Center (36 E 8th St).

Friday sessions will include "Invertebrates and the evolution of consciousness", "Do fish feel pain?", and "Animal consciousness and ethics".

Saturday sessions will include "Animal self-consciousness", "Animal consciousness and theories of consciousness", and a panel discussion.

A detailed schedule will be circulated closer to the conference date.

Registration is free but required.

\section{Register here.}

\section{See also the conference website}

